\title{
An Examination of Connections in Mathematical Processes in Students' Problem Solving: Connections between Representing and Justifying
}

\author{
Despina A. Stylianou ${ }^{1}$ \\ ${ }^{1}$ The City College of New York, Department of Secondary Education, New York, NY, USA \\ Correspondence: Despina Stylianou, School of Education NAC 6/207B, Convent Ave and 138th Street, New \\ York, NY 10031, USA. Tel: 1-212-650-5037. E-mail: dstylianou@ccny.cuny.edu
}

Received: January 23, 2013

Accepted: February 26, 2013

Online Published: April 2, 2013

doi:10.5539/jel.v2n2p23

URL: http://dx.doi.org/10.5539/jel.v2n2p23

The research reported here was supported in part by the National Science Foundation under Grant \# REC-0447542. Any opinions, findings, and conclusions or recommendations expressed in this material are those of the authors and do not necessarily reflect the views of the National Science Foundation.

\begin{abstract}
Representation and justification are two central "mathematical practices". In the past, each has been examined to gain insights in the functions that they have in students' mathematical problem solving. Here, we examine the ways that representation and justification interact and influence the development of one another. We focus on the problem solving activity of 12-14 year-old students. Overall, this work highlights that the two practices are tightly connected. Students' representations impact the way they form generalizations and subsequently justify their work. The work also provides insights in the development of representation and justification within the problem solving process. This work also provides insights where students' representational practices may hinder the development of advanced justifications, and provides directions for pedagogy and further research.
\end{abstract}

Keywords: representation, mathematical processes, justification

\section{Introduction}

Representation and justification are two central aspects of "mathematical practice" - one of the main foci of the strategic agenda and guidelines for a long-term research and development program that could contribute to practice and policy in mathematics education identified in the USA by the Mathematics Study Panel: "Our second focus concerns the teaching and learning of mathematical practices. [These] involve more than what is normally thought of as mathematical knowledge. This area focuses on the mathematical know-how, beyond content knowledge, that constitutes expertise in learning and using mathematics" (RAND Mathematics Study Panel Report, 2003, p. xviii). The panel argues that the identification, analysis, and development of these practices is a critical priority if educators are to be able to help all students attain mathematical proficiency - a view that is now being reiterated in United States and emphasized by the Common Core Standards panel (National Governors Association \& Council of Chief State School Officers, 2010).

In this work the focus is explicitly on the mathematical practices of representation and justification. First, the domain of representation includes the choices we make for expressing and depicting mathematical ideas and the ways in which we put them to use. Representations can be drawings, diagrams, physical models, and also mathematical symbols - in short, the range of symbolic tools that can be used for representing aspects of the world. As many have emphasized (e.g., Olson, 1994; Grosslight, Unger \& Smith, 1991), representing is not a matter of simply copying what one sees. Instead, it involves inventing or adapting conventions of a representational system for the purpose at hand. It has been argued that the evolution of representational ability and the evolution of mathematical conceptions are mutually supportive and occur hand in hand (Lehrer \& Schauble, 2002). Hence, the development of students' ability to represent ideas in different ways is fundamental to mathematical work. However, as Goldin and Kaput (1996) point out, in the school curriculum as it is most often implemented, the most attention is paid to formal symbolic systems of representation, while much less attention is given to the (equally 
mathematical) imagistic systems and to heuristic systems of representing, planning and decision making for effective problem solving.

Justification centers on how mathematical knowledge is certified and established as "knowledge." Understanding a mathematical idea means both knowing it and also knowing why it is true. Although "understanding" is part of the contemporary reform rhetoric, the reasoning of justification, on which understanding crucially depends, is largely missing in much teaching and learning. Many students, even at the university level, lack not only the capacity to construct proofs (a formally structured view of justification), but even the appreciation of what a mathematical proof is. That mathematical justification involving reasoning that is more general than what we typically call "proof" is often overlooked and under-appreciated. Arguments for proof being the soul of mathematics (Schoenfeld, 2009) and that "proof is not a thing separable from mathematics... [but] is an essential component of doing, communicating, and recording mathematics" (Schoenfeld, 1994, p. 76) reinforce the centrality of justification in mathematical thinking. Moreover, not only does the act of proof "distinguish mathematical behavior from scientific behavior in other disciplines" (Dreyfus, 1990, p. 126), it also serves as a didactic for learning mathematics (Hanna, 1990, 1995; Hersh, 1993). As such, one would expect justification and proof activities to be embedded in developmentally appropriate ways in curricula at all levels. However, due perhaps to low student expectations or our own limited understanding of how to make this act of justification and proof accessible to a wider population of students, it has had only a limited place, if any, in school curricula.

This increasing awareness that representation and justification are central to mathematics is clearly reflected in recent reform efforts. This is particularly obvious in the position of the National Council of Teachers of Mathematics [NCTM] in the USA who in their most recent national standards document they elevated the status of representation and justification; not only have representation and justification been upgraded to two of the standards in this document, but they are expected to be a part of the mathematics education of all students (NCTM, 2000). With respect to representation, the NCTM recommends that students "create and use representations to organize, record, and communicate mathematical ideas; select, apply, and translate among mathematical representations to solve problems; and use representations to model and interpret physical, social, and mathematical phenomena" (p. 64). With respect to justification, it recommends that students should be able to "recognize reasoning and proof as fundamental aspects of mathematics, make and investigate mathematical conjectures, develop and evaluate mathematical arguments and proofs, and select and use various types of reasoning and methods of proof" (p. 56). In short, NCTM is emphasizing that representation and justification should be a part of all students' mathematical experiences in order to deepen and extend learning and to democratize access to these ideas to a broader population of students. And while the reform community embraces these recommendations, it is also recognized that the road to their implementation will be a long one. Not only are representation and justification found to be challenging aspects of mathematics, but also, their incorporation in mathematics teaching places significant demands on teachers who have received little or no training on fostering these mathematical practices (see, e.g., Knuth, 2002; Stylianou, 2010).

Recent research efforts have been exploring the use of representation and justification in students' mathematical work, and have documented the challenges associated with the use of each. However, few have focused explicitly on the interplay between the two and the connections in the challenges faced in advancing students' facility in the use of these practices. Nonetheless, the two activities are closely related. Weber and Alcock (2009) argue that "learning to prove in college classrooms requires students to work within a representational system" (p. 324). It is reasonable to assume that a limited representation of a mathematical concept might impact the ways in which a student uses it to produce a proof. If, for example, a mathematical concept is only represented in a symbolic format, students might find it difficult to unpack the "semantic" (i.e., conceptual) aspects of this definition. Similarly, a visual representation of the same concept might allow for a certain level of exploration but, if not accompanied by a symbolic representation, it might confound the student's ability to produce a proof. Certainly, the ways in which students represent their work will influence the tools that they can bring to bear when justifying their work. But, a proof or an argument might also have an impact on the way the mathematical concept is further represented by students; in other words, proofs also influence students' representation of mathematical concepts. As Otte (1994) argued, "a proof is also expected to enrich our intuition" (p. 310). The relationship in the development of mathematical processes is often bidirectional (as shown by Ellis (2007) in her work on the interplay between generalization and justification). In conclusion, because both representing and justifying can influence the development of one another, it is important to understand the nature of this interrelated development; an examination of these relationships is the aim of this study. In this work, we explore the relationship between the two. 


\subsection{Background on Representation}

In the past decade representation has been increasingly viewed as a "useful tool for communicating both information and understanding" (NCTM, 2000). But, despite the renewed interest in representation, we now know that students face difficulties when negotiating the various forms and functions of representations. In fact, as NCTM proceeds to note, "the term representation refers both to process and product-to the act of capturing a mathematical concept or relationship in some form and to the form itself" (NCTM, 2000, p. 67). Representation, indeed, has a dual nature, which might help us begin to understand the complexities with which it is associated.

Let us first consider "representation as process" - a widely studied construct in mathematics education (see, for example, Kaput (1991), and Janvier (1987)). Janvier (1987) identified "translation" which he defined as a continuous movement among the various representations of one mathematical construct during problem solving. Kaput (1991) discussed "encoding, syntactic elaboration and semantic elaboration" - all three are processes involved in the reading of representations. Turning now to "representation as product", again several studies identified the difficulties students face in understanding graphs (Leinhardt, Zaslavsky \& Stein, 1990) - difficulties that are contrasted by evidence that experts (individuals who are skilled in problem solving) in fact rely on visual representations as tools that add information in this process (e.g., Ochs, Jacoby \& Gonzales, 1994; Stylianou, 2002). Indeed, representation use can be quite complex, not only from a cognitive perspective, but also in the social domain. Monk (2003) argues that the social aspects of representation may also impact student understanding. Others are now addressing complexities in representation use in group settings and interactions (e.g., Silver et al., 2005). These studies highlight discourse in representation use and how classrooms and groups of students establish meaning during this process (e.g., Cobb, Yackel \& McClain, 2000; Sfard, 2000).

Earlier work (Pimm, 1987; Roth \& McGinn, 1997; Stylianou, 2011), proposed various uses and functions of representation taking into consideration both cognitive (use by an individual during problem solving) and social (used in public) functions of representation. Further, this work attempted to look at the use of representation both as a product (static) and as a process (dynamically evolving). In a summary, Stylianou (2011) suggests that uses and functions of representation in students' problem solving work include the following:

- As a tool to process information-one might use a representation as a means to put together the various aspects of the problem and to examine how they contribute to the problem solving process.

- As a tool for recording information-one might use a representation as a tool that combines all the information instead of keeping it "all in the mind".

- As tools that allow exploration of tasks or concepts-one might use the representation as an adaptable tool device that allows for experimentation with concepts and provides more information.

- As monitoring and assessing tools that evaluate progress in problem solving - representations may be used to monitor problem-solving progress and to make informed decisions when selecting subsequent goals and maintaining or revising current plans.

- As conscription tools - devices to negotiate and co-create meaning and strategy with fellow problem solvers. The representations form a shared interactive space that facilitates communication, as they may be used as a common language tool.

- As presentation tools - students use these representations to share information both formally and informally, regarding both the process and the end result.

In the work, we use the above classification to organize and understand children's representation processes.

\subsection{Background on Justification and Proof}

Harel and Sowder $(1998,2007)$ argued that proving or justifying a mathematical conjecture involves ascertaining (convincing oneself) and persuading (convincing others). A proof scheme consists of what constitutes ascertaining and persuading for a person. They proposed three levels of student proof schemes: (1) external conviction proof schemes; (2) empirical proof schemes; and (3) analytical proof schemes.

External conviction proof schemes are ones in which students build arguments or accept the validity of an argument based on sources external to the student, whether based on the ritual or the form of the appearance of the argument, the word of an authority, or some symbolic manipulation without reference to the symbols' meaning. Empirical proof schemes can be either inductive or perceptual. When a student attempts to establish a conjecture using examples or specific cases, he/she is considered to have an inductive proof scheme. In a perceptual proof scheme, a conjecture is validated via rudimentary mental images, that is, "images that consist of perceptions and a coordination of perceptions but lack the ability to transform or to anticipate the results of a transformation" (Harel 
\& Sowder, 1998, p. 255). A proof scheme is characterized as analytical when the validation of conjectures is obtained by the use of logical deduction. Analytical proof schemes can be either transformational or axiomatic. A transformational proof scheme involves goal-oriented operations on objects. The student operates with a deductive process in which she considers generality aspects, applies goal-oriented and anticipatory mental operations, and transforms images. An axiomatic proof scheme goes beyond a transformational one, in that the student also recognizes that mathematical systems rest on (possibly arbitrary) statements that are accepted without proof.

\section{Statement of the Problem}

Recent reform efforts in mathematics education describe a vision which practices are central to mathematics teaching and learning. Hence, there is a clear need for work that articulates not only the various functions of each of these practices, but also the ways in which these practices interact with and inform one another. This paper aims to examine the ways that the practices of representation and justification interact and influence the development of one another.

\section{Methods}

The work reported here is part of a larger study that examined problem solving among middle school students. Our setting was a public urban school that reflected the ethnic diversity of the community in which it is located (about $98 \%$ of the students are reported as coming from ethnic minorities and $73 \%$ of the students come from families at the poverty level). We conducted our work in a $6^{\text {th }}$ grade classroom of 24 students.

We strongly believe that mathematical practices such as representation or justification occur when students engage in cognitively demanding tasks (Stein et al, 2010) which invite students to represent solutions, come up with conjectures and, subsequently provide justifications. Students at first worked using problems with growth patterns (e.g., growing rectangle trains, and the "swimming pool" task). Figure 1 shows the introductory task, the "party task. This task was followed by a task in which the "tables" were triangles and subsequently with a task which asked students to generalize their patterns to "any regular-polygon-shaped tables". Subsequently, the students returned to a published curriculum (Kindt, Mabels, Meyer, \& Pligge, 1998). Tasks focused on operating on unknowns, particularly trading equivalent quantities (for example, the tasks used contextualized situations to encourage students to think about if $m=3 k$, then how can one we figure out $2 k+m=15$ ?). Overall, the three weeks introduced students to generalizing patterns, using variables and operating on unknowns and variables. The teacher started each lesson by introducing the task verbally. Students were given a few seconds to think about each task on their own and ask clarifying questions (if they had any). Subsequently, students were asked to work in groups of four to solve the task. The groups were kept consistent throughout the three weeks. Students were given about 40 minutes to solve the task and were asked to be prepared to share their findings with the class. During this time the teacher visited each group and limited her role in asking questions to help students explain their reasoning. For example the teacher asked students to explain what their drawings represented and why they chose these representations. The teacher then invited some students to share with the whole group and the remaining students were invited to ask questions for understanding, but also to make connections between different solutions. In accordance with Stein et al (2008) recommendation, the teacher purposefully chose particular solutions to be shared, particularly those that helped advance the mathematical goals of the lesson (generalizing and introducing variables). In particular, the teacher invited some students to share with the whole group and the remaining students were invited to ask questions for understanding, but also to make connections between different solutions.

"We plan on having a party for the upcoming presidential elections. We want to sit with our friends and watch the results as they announced on TV. A party rental company will bring several small square tables (each side fits one person) that we will put together to form one long table. How many people can we fit in our party if we rent several such tables?".

Figure 1. The "party task"

All students were also interviewed at the end of the experiment. Each student was asked to solve a growth pattern task. We video-recorded and transcribed all lessons. 
We analysed our data using Creswell's (1998) grounded theory paradigm. In other words, we segmented all transcripts in parts using the ideas of representation and justification as guides. Subsequently, we coded each of these segments using the researcher-generated codes that we earlier identified. With respect to representation we used the six types of representation use proposed by Stylianou (2011) and with respect to justification use, we used the three categories suggested by Harel and Sowder (1998) - both described in the previous section.

We grouped codes using themes that emerged from them and subsequently searched for trends over time. A second round of analysis focused primarily on these trends and shifts that were identified in earlier analysis. We aimed to confirm (or reject) evidence of these shifts. Finally, we looked for relations between the use of various types of representations and justifications. Again, once such relations were identified, the data were re-examined to establish conjectures. Finally, all protocols were independently coded for inter-coder reliability.

\section{Results and Discussion}

Our analyses revealed four themes of coordinated efforts of representation and justification in our data. Here, we present and define these themes and we use episodes from the teaching experiment to further illustrate them.

\subsection{Iterative Cycles of Representing and Justifying}

We begin this section by illustrating and analyzing first, the actual interaction of representing and justifying. Our data show several instances of intertwined actions of representation and justification and these were at the center of our analysis.

In the two episodes below students explored the party table task (see figure 1). In the first episode, Gareth had started to represent the task and as he did, he engaged in a conversation with Emily. At this stage, the two students attempted to understand the implications of pulling square tables together to form one long rectangular sitting arrangement. Each student argued and negotiated their own understanding while using the representation to justify these insights. Similarly, in the second episode, Justin, Anna and Tyler are grappling with the same question, while again, their representation is at the center of the discussion:

Episode I:

Gareth: $\quad$ But if you said that it eliminates one, then it's gonna...

Emily: Exactly, cause, because if it eliminates...

Gareth: No it actually eliminates two, doesn't it, because you got, one, two, three, four, five, six, and there's supposed to be seven, and eight. Cause

Emily: $\quad$ So you draw one table, you put each person on each side

Gareth: Yeah

Emily: $\quad$ Then, you, you, uh

Gareth: You add another table

Emily: $\quad$ Yeah, you add another table, and then you put each person on each side and

Gareth: But, you know, have to eliminate that because he's going to be squished.

Ethan: So you're saying there's going to be four people at each table, or three?

Emily: Three. Three at each table.

Gareth: No, no, look, you eliminate two...

\section{Episode II:}

Anna: If you connect two of them... it's minus one person.

Justin: Yeah but does it, look, but because you have

Tyler: $\quad$ No, but look, because you are clearing the table, you could just add another person.

Justin: Yeah, because it's sitting on that side, right behind the other person.

Tyler: $\quad$ Yeah, so you just, so it would make more

Anna: $\quad$ But she said on each side one person. 
Justin: $\quad$ Yeah, so then you have another person there, there, there, and there, and if you keep on doing that, you're going to minus two all the way. Like, four sets of, you know... yeah four sets of two, no wait, four

Anna: $\quad$ Oh yeah, it's minus two...

In the discussions above students argued extensively about the number of eliminated guests. One common reference in all discussions, was that students' arguments and justifications were strongly grounded in the context and the representation they created. As they started exploring the task through their drawing they realized that the task was more complex that they had initially anticipated - adding tables does not simply add four guests, but there is a process of elimination of a few guests in order to accommodate more tables. Their new insight led them to reconsider their first conjecture (that tables would be one forth the number of guests). One of the students, Emily, realized that one person would have to leave the arrangement as the tables would be put together. Her partner, Gareth, suggested that, in fact, it would be two people that would have to leave. The representation was used to better understand how guests and tables interacted so they would be able to argue with their peers. Similarly, in the second episode, the three students are trying to understand whether one, two or three guests are eliminated as tables come together.

The students here used their representation as an exploration tool, that is, they used their initial recordings to explore the problem further. While doing this exploration, manipulated their representation, adding or removing detail. They also used their representations as a conscription tool; to discuss and understand their strategies with fellow students. Their representations formed a shared interactive space that facilitated communication. This, in fact, is an important first step towards justification; students' social actions of sharing and negotiating their representations with their peers was a natural first step towards the production of proof.

Fosnot and Dolk (2002) argued that "at the heart of mathematics is the process of setting up relationships mathematically in order to communicate them to others" (p. 8). Central to this, is the process of representing. Students, similar to mathematicians, represent problem situations and use these representations as devices in advancing their own understanding and communicating their thinking to their peers (Stylianou, 2011). As students explore problem contexts, they create representations as part of processing and exploring mathematics and these representations become models of their thinking. But, representations are rarely invented in their final form. Rather, students create their representations dynamically in iterative cycles - what has been described as "chains of signification" (Gravemeijer, 2002; Meira, 2002). This theory suggests that a sign (a signifier of another concept or object) gradually itself acquires meaning, becomes signified, so a person can act on it as if it were an object. Hence, the process of a representation often involves iterative cycles of representing and gradually altering representations while at the same time gaining further insights into the task.

This work suggested an added dimension during these iterative cycles of representation creation; it showed that each of these cycles also involved a social action with respect to representation, a sharing of student work with peers that involved a justification. Students recorded their representation actions on particular tasks and proceeded to share these with their peers. In the process of doing so, the representations functioned as conscription devices; the sharing of the representation allowed for a negotiation that often led to further elaboration in the representation and advanced the student understanding. In other words, students' representations increased in sophistication, over time, both within single episodes and over the three-week experiment.

\subsection{Representations Related to Inductive Reasoning and Justification}

A recognition that the iterative cycles of signification in students' representations involved justification extended the question towards the type of justifications that these representations might facilitate or necessitate. Students used their representations as flexible devices that allowed for exploration of concepts and gave them more information into the task at hand. As they shared these representations with their peers, the products and the reasoning behind them were not accepted by their peers unquestioned; students negotiated, asked questions, explored and probed further. Their goal was to generalize findings in ways that were useful in the task.

The nature of the students' explorations within their representations had an impact on their generalizations and, subsequently their justifications. Students often proceeded in their explorations by elaborating on their representations. They added new information on their representations, more shapes, people, and signs that signified actions. In other words, students added contextual details and grounded their representations in the task context. In the case of the pattern-generalization tasks (e.g., the "party task"), the children included drawings of people "squished" or crossed over, and their interactions with other students remained grounded firmly in the context of the task. In the case of the trading tasks (e.g., "one elephant is as strong as two horses and an ox"), 
students drew pictures of animal trades. The three excerpts below illustrate students' grounding in the context:

Episode I:

Kate: Oh, so like, are you, like there's ten tables, right? You draw the tables, right? All you have to do is count the peop- the little circles that you drew, that tells you the amount of people that are going to be there. Each table equals two people because if they get like together then those two, those two sides would have no people because they squished.

$[\ldots]$

So, there's a person here, doot, doot, doot, doot [with each "doot" she touches a different square] right, they're sitting down. ... It's going to be three, two, two, two, two, two, two ...

Episode II:

Teacher: Can you predict how many it's going to be? [referring to party task]

Julie: $\quad$ Yes... three, two, two... three more, wait, wait, wait, it's kind of confusing... [resumes drawing].

Jack: $\quad$ It's 32

Julie: Where are you getting the thirty two? [...] Can you use the tiles?

Episode III:

Jordi: It says four oxen are as strong as five horses, I'm thinking... how do you get them to be like an elephant? I'm going to have to draw the elephant [...] If you make [the elephant] more fat, it will take as much space as the horses?

In the first episode, Kate, had an arithmetical view in solving the task (counting one-by-one, tagging drawings as she counted). The representation she built, as well as her discussion suggested that she relied on the context of the task. Similarly, Julie when asked to predict the number of guests for a new number of tables, had to reconfigure her representation and use it as a counting device, both to find the answer and to make sense of her peer's response. Finally, in the third episode, Jordi is trying to understand the equivalence using his representation; issues such as scale and size of drawings are important factors in his reasoning.

This was not a surprising finding. Bieda and Nathan (2009) showed that contextual representations may impact students' performance in a negative manner. Their studies, as well as those by Kaminski, Sloutsky and Heckler (2008) suggested that over-contextualizing leads students to focus on surface or superficial properties of tasks as opposed to the deeper structure that underlies the context. As a result that might lead to transfer difficulties and incomplete learning.

This very arithmetical view of the task can be viewed as an inductive justification - an empirical proof scheme. Kate's argument was grounded on quantitative information. And while Kate could see a certain pattern in the growth of guests ("two, two, two..."), the pattern was quantitative and strongly linked to her action ("doot, doot, doot...") on her representation. Kate, in this occasion did not provide a generalized, analytical argument or explanation.

In these cases, students who gradually elaborated on their representations tended to be the ones who also produced inductive arguments. That is, students used these contextual details to facilitate numerical computations. Hence, their justifications suggested the use of empirical proof schemes. This is not surprising; Thompson (1988) noted that students' reliance on numerical computations leads to an empirical view of proof. It is only when students begin to attend to the quantitative relationships that students might shift to also producing deductive justification arguments.

\subsection{Representations that Promote Deductive Reasoning}

The transformational proof scheme assumes that students attempt to validate a conjecture using deductive reasoning and logic. Harel and Sowder (1998) note that students who operate within a transformational proof scheme often "consider generality aspects of an observation, apply goal-oriented and anticipatory mental operations, and transform mental images as part of the deduction process". In our data, students who developed deductive arguments were ones that within the process of exploring concepts and problems at hand gradually produced abstracted representations, that is, representations from which context had been gradually removed. 
Indeed, antithetical to those students who tried to elaborate their representations contextually, other students tried to operate on abstract objects by removing context gradually:

Seth:

You should just put ten times two, because there's ten squares, right? And, on each side, so there's ten times two, on both sides, there's ten. So it's ten times two. And you add two, because there's two more edges.

Anna: $\quad$ So ten, times two equals twenty

Seth: $\quad$ And plus two.

The students above are considering the entire figure and generalizing its properties. Seth is not counting tables or people; he has generalized that there will be as many seats as the length of the table arrangement, twice, plus two seats at the end. Similarly, another student, Molly, was considering one long rectangle and recognized that individual tables are now irrelevant in her solution. It was when contextual detail was removed rendering the representation more abstract that generalizations appeared in students' work. The abstraction was evident also in students' discourse. They were now discussing edges, squares and length, not tables. Indeed, once the task about a party was transformed into a "square task" (a geometric object that students understood quite well), new insights emerged.

Earlier work on experts (e.g., Dubinsky, 1999; Simon \& Simon, 1978; Stylianou \& Silver, 2004) had shown that, when solving new problems, expert mathematicians often engage in iterative cycles of representation and exploration. Experts represent their thinking, use that representation to experiment and explore, and once reaching a new insight they adjust or re-create their representations to reflect their new understanding. The process of representing is dynamic and fluid. Here, students, too, gave us a glimpse of an ability to engage in these iterative cycles of representing and exploring. Students who advanced further into these cycles were more likely to create abstracted representations.

Furthermore, the removal of context, hence more abstract representations of the task, facilitated the process of making connections among tasks or concepts. Once students noticed similar objects or realized that they were engaging in similar actions as they did in earlier explorations ("we are doing the same as the other time") in their representations, they were more likely to establish connections. This was apparent in a later session when students were given a new growth task, this time about triangles. Those students whose representations were more abstract were likely to notice connections with their earlier work on the "party task":

Episode I:

Sarah: It's just the same thing as that one it's just that one side is cut off... It's like the tables! You do the same exact thing that you were going to do there. [...] one table can fit 3 people, two tables can fit 4 people... [...] it's adding 1 to the tables.

Episode II:

Simon: $\quad$ Ok, we should look for a rule, right?... one triangle has three sides then if you added another [triangle] that's six sides all together but if you put it together it equals a rhombus and that's a four-sided figure which is a quadrilateral. And you are taking those two sides. [...] it's like the square tables, so it's the number of tables plus $2 \ldots$ it's half?

The two students (not working together) became aware of the task similarity simply by using their representations. The removal of the contexts allowed students to form these connections which were geometric in nature. The two students' generalized view of the pattern suggested a transformational proof scheme, that is a deductive view of justification. While this is a tentative suggestion (as we did not administer specific tests to claim with certainty that Sarah or Simon held deductive proof schemes), there are several indications that the two students acted within this scheme. Sarah, in particular, searched for structural similarities between the two growth pattern tasks. She anticipated a regularity and the possibility of finding a generalized pattern; in fact, as Harel and Sowder describe, Sarah applied "goal-oriented and anticipatory mental operations, and transform(ed) mental images as part of the deduction process" (1998, p. 261). Sarah acted on the representation in search and expectation of a regular pattern and while doing so she justified the steps she was taking using several different ways, including the use of numerical examples.

Simon searched for a particular relationship between the tasks and within the parameters of the new task; once he noticed that two triangles might be put together to form a quadrilateral, he searched for a relationship in the pattern: "it's half?". One may argue that this attention to a relationship, rather than discrete data and empirical findings, 
invited the use of a transformational proof scheme. Once removed from particular numbers, students eased themselves into operating on the new objects they had created. Their previous experience also prepared them to expect certain generalizations and abstractions.

This finding resonates earlier findings of Ellis (2007) who identified three types of generalizing that promoted the transformation proof scheme: "generalizing action of searching for relationships, the generalizing action of extending, and the reflection generalization of an identification of a continuing phenomenon" (p. 222). In that work, similar to this study, Ellis concluded that "the students' actions suggested that searching for the same relationship was not only connected with the use of the transformational proof scheme but may also have promoted its use. By turning their attention to relationships, students constructed new mathematical objects. Through repeated reasoning with the construction of new mental objects as relationships between existing objects, students honed their ability to operate on objects. In addition, as students searched for the same relationship, they anticipated that a certain relationship would remain stable throughout the data" (2007, p. 222). Indeed, students' representational, generalization and justification processes appear to be highly related and coordinated and further work could identify more such relationships.

\subsection{Deductive Reasoning Influencing Representation}

Students who appeared to operate within a transformational proof scheme (deductive arguments) often returned to their representations and acted on them so as to represent more general cases. This was particularly noteworthy, as students had already formed abstracted representations and argued using logical, deductive-in-nature arguments. Yet, these students in some occasions returned back to their representations and took a few extra steps towards producing more abstracted images or symbolic expressions.

An illustrative example was offered by Ethan as shown in Figure 2. Ethan had already produced a relatively abstract representation and appeared to operate within a transformational proof scheme. When the teacher asked him to further explain his reasoning, Ethan turned to the blackboard and took yet another iterative step in his representation, resulting in a highly abstract representation. Ethan now represented the row of tables with a straight segment. He further recorded his pattern using language more distanced from the concrete scenario: "sides times 2 plus 2". It is possible that once Ethan was within the frame of mind of the transformational proof scheme, particularly using goal-oriented and anticipatory actions in transforming images in his mind and on paper, Ethan saw the need to produce a representation that fully illustrated his current way of reasoning.

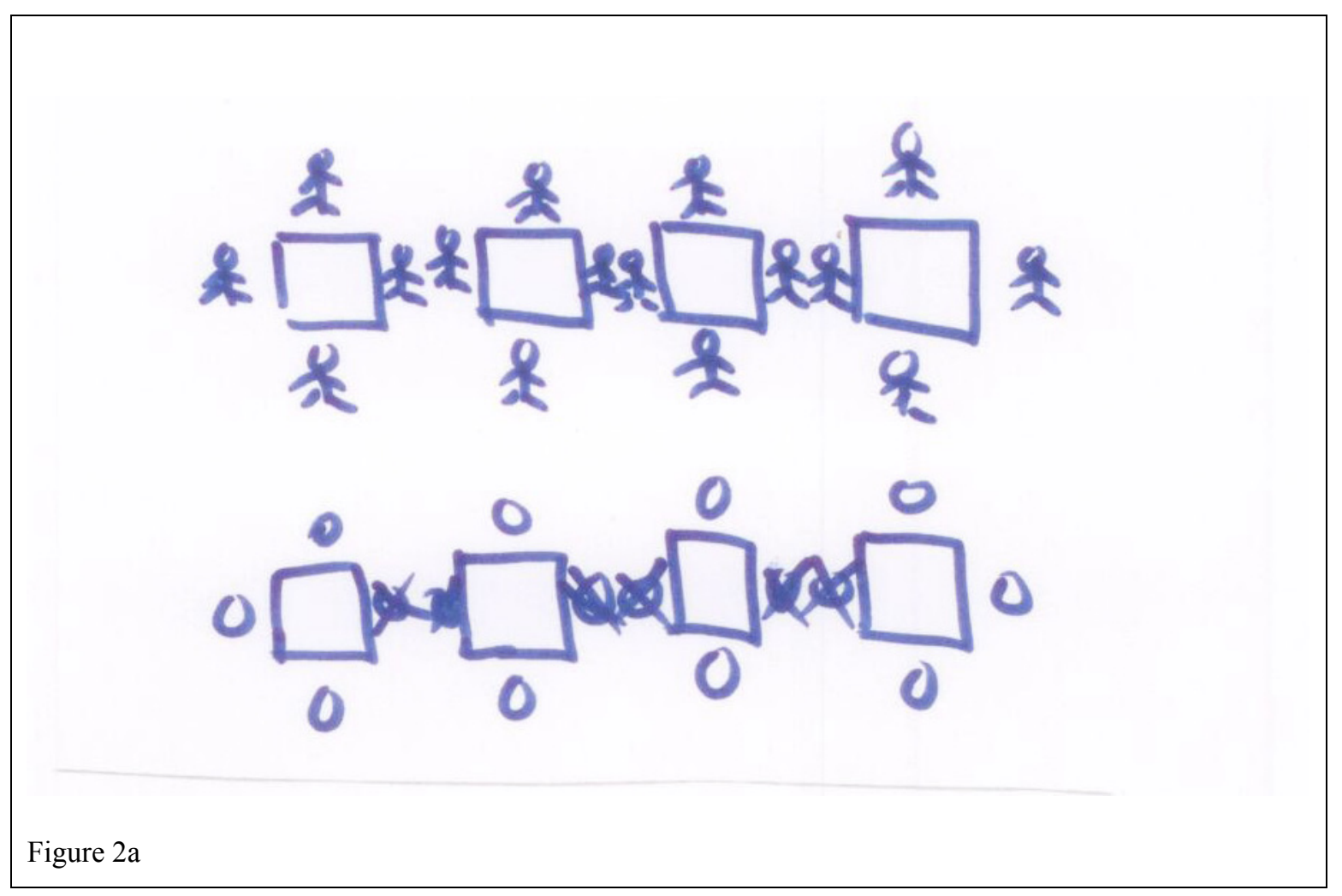




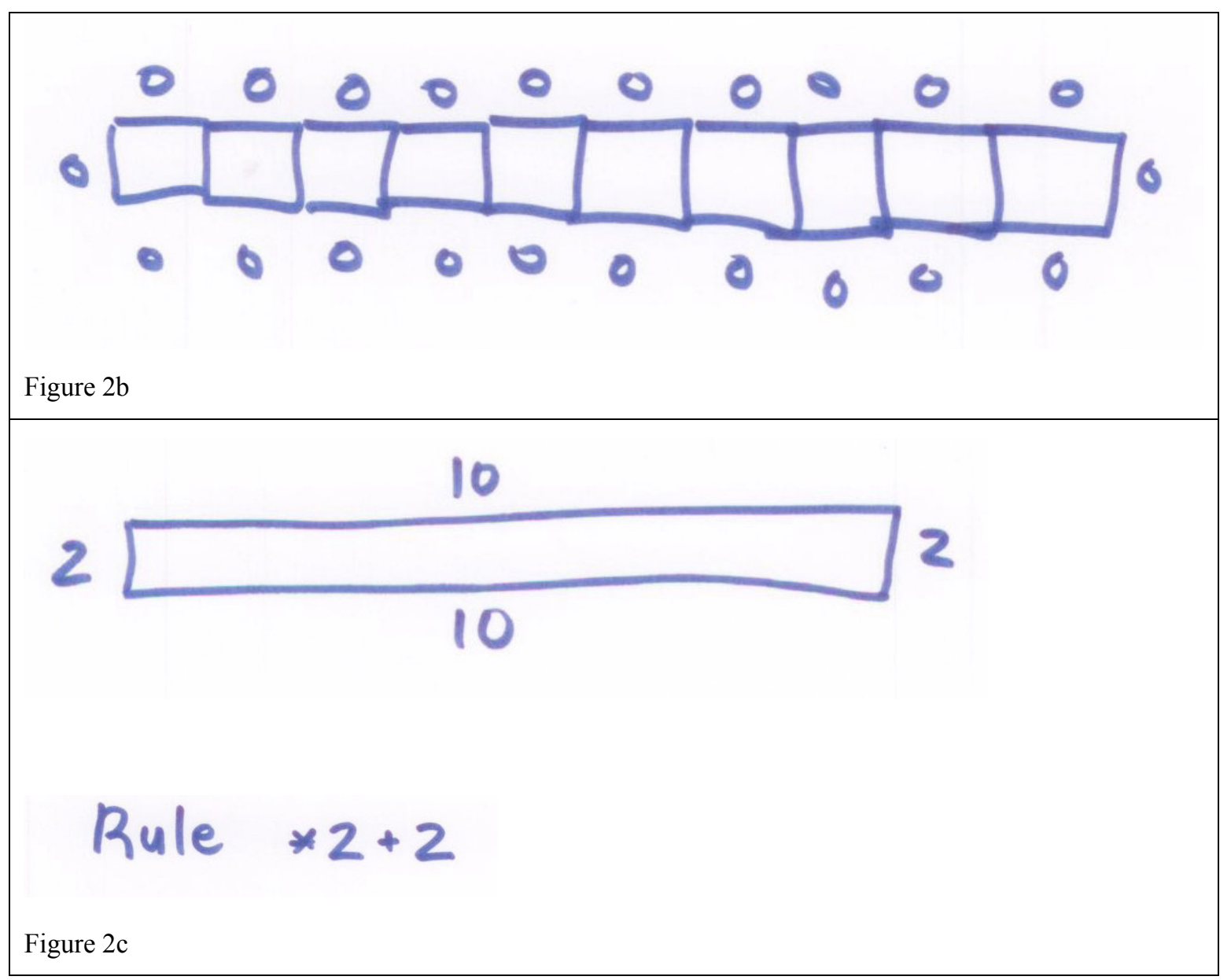

Figure 2. Iterative cycle of representation

This last theme definitely appeared more sparsely in the data. This is possibly due to the fact that fewer children operated within the transformational proof scheme than within the empirical scheme. It is also important to note that the identification of such episodes within classroom data is hard; they often occur briefly within the lively classroom turmoil; or they appear in discrete episodes making it difficult for the observer to identify the continuity. However, they do exist, and once noticed they offer valuable instructional opportunities for the teacher to pursue.

\section{Final Remarks and Pedagogical Implications}

This study aimed to examine the nature of the interaction and relationship between representing and justifying two mathematical practices of central importance in students' problem solving. Our goal was to help the field move towards a better understanding of these practices and their interactions when they occur together using empirical grounding.

While earlier work has pointed to possible such connections and interactions, there has not been a systematic investigation, particularly within the context of classroom instruction. Our goal was not to simply identify these practices and, possibly, the difficulties that students might face when using them during problem solving; a more current view in mathematics education emphasizes a broader view of the teaching and learning of mathematics, looking beyond difficulties and deficits and embracing how students learn and come to know (Steffe \& Kieren, 1994).

Overall, this work furthers our understanding of the close connections between representation and justification, identified four main categories of interactions: coordination of individual action (recording) and social action (sharing-justifying), representations that facilitate inductive reasoning and justification, representations that promote deductive reasoning, and deductive reasoning as it influences representation. It is important to note that these four types of interactions are not hierarchical nor do they occur in the work of students in particular chronological order. While the first theme, coordination of recording and justifying, is broader in nature and 
appears to weave through the remaining three categories, overall, our data suggested that students use the four categories at various parts of the problem solving activity. Justifications and representations influenced one another in this process dynamically in iterative cycles. Students' representations impacted the ways in which they justified their solutions and strategies to their peers, while, at times, their justifications caused them to re-think their representations. The study indicates that broader representations, less context-dependent are more likely to be accompanied by generalized ways of reasoning and deductive-oriented justifications. Broader representations helped students focus their justifications using "semantic" (Weber, 2001) aspects of the mathematical ideas at hand which lead to these deductive-oriented justifications. Note that, as this work relates to middle school students, there is little discussion about "writing proofs" or the syntactic aspect of the justification and proving process.

The findings here can also be discussed from a representation perspective: This work adds to the body of literature that illustrates how the meaning and utility of representation shifts during the problem solving process (Hall, 1989; Pimm, 1987; Stylianou, 2011). Often teaching focuses on representation as a presentation tool and less so on how a student might use representation differently depending on its role and utility in problem solving. This is something that teachers need help to develop awareness and subsequently incorporate in instruction. A representation not only impacts one's presentation of a solution, but may also impact the way one justifies a solution. As schools are encouraged to emphasize and pursue proof and justification beginning in early grades (and not only as a topic in late high school and college), educators need to pay close attention to these interactions of justification with other processes such as representation and acquire the skills to help students develop their ability to both form and use suitable representations in their problem solving process.

\section{References:}

Bieda, K., \& Nathan, M. (2009). Representational disfluency in algebra: Evidence from student gestures and speech. ZDM-The International Journal on Mathematics Education, 41, 637-650. http://dx.doi.org/10.1007/s11858-009-0198-0

National Governors Association, \& Council of Chief State School Officers. (2010). Common Core Standards Initiative. Retrieved from http://www.corestandards.org/

Cobb, P., Yackel, E., \& McClain, K. (2000). Symbolizing and communicating in mathematics classrooms: Perspectives on discourse, tools, and instructional design. Mahwah, NJ: Lawrence Erlbaum.

Creswell, J. (1998). Qualitative inquiry and research design: Choosing among five traditions. London: Sage.

Dreyfus, T. (1990). Advanced mathematical thinking. In P. Nesher, \& J. Kilpatrick (Eds.), Mathematics and cognition: A research synthesis by the International Group for the Psychology of Mathematics Education (pp. 113-134). UK: Cambridge University Press. http://dx.doi.org/10.1017/CBO9781139013499.008

Dubinsky, E. (1999). Determining linearity: The use of visual imagery in problem solving. In Proceedings of the $21^{s t}$ Annual Meeting for the Psychology of Mathematics Education - North America (PME-NA) (pp. 245-252). Cuernavaca, Mexico: Centro de Investigación y de Estudios Avanzados del IPN and Universidad Autónoma del Estado de Morelos

Ellis, A. (2007). Connections between generalizing and justifying: Students' reasoning with linear relationships. Journal for Research in Mathematics Education, 28(3), 194-229.

Fosnot, C., \& Dolk, M. (2002). Young mathematicians at work. Portsmouth, NH: Heinemann.

Goldin, G. A., \& Kaput, J. J. (1996). A joint perspective on the idea of representation in learning and doing mathematics. In L. P. Steffe, P. Nesher, P. Cobb, G. Goldin, \& B. Greer (Eds.), Theories of mathematical learning (pp. 397-430). Mahwah, NJ: Erlbaum

Gravemeijer, K. (2002). From models to modeling. In K. Gravenmeijer, R. Lehrer, B. van Oers, \& L. Verschaffel (Eds.), Symbolizing, modeling and tool use in mathematics education (pp. 7-23). Dordrecht: Kluwer. http://dx.doi.org/10.1007/978-94-017-3194-2_2

Grosslight, L., Unger, E. J., \& Smith, C. (1991). Understanding models and their use in science. Journal of Research in Science Teaching, 28(9), 799-822. http://dx.doi.org/10.1002/tea.3660280907

Hanna, G. (1990). Some pedagogical aspects of proof. Interchange, 21, 6-13. http://dx.doi.org/10.1007/BF01809605

Hall, R. (1989). Exploring the episodic structure of algebra story problem solving. Cognition and Instruction, 6 , 223-283. http://dx.doi.org/10.1207/s1532690xci0603_2

Hanna, G. (1990). Some pedagogical aspects of proof. Interchange, 21, 6-13. 
http://dx.doi.org/10.1007/BF01809605

Hanna, G. (1995). Challenges to the importance of proof. For the Learning of Mathematics, 15(3), 42-49.

Harel, G., \& Sowder, L. (1998). Students' proof schemes: Results from an exploratory study. In A. H. Schoenfeld, J. Kaput, \& E. Dubinsky (Eds.), Research in College Mathematics Education III (pp. 234-283). Providence, RI: AMS.

Harel, G., \& Sowder, L. (2007). Toward a comprehensive perspective on proof. In F. Lester (Ed.), Second handbook of research on mathematics teaching and learning. Greenwich, CT: Information Age Publishing.

Hersh, R. (1993). Proving is convincing and explaining. Educational Studies in Mathematics, 24, 389-399. http://dx.doi.org/10.1007/BF01273372

Janvier, C. (1987). Translation processes in mathematics education. In C. Janvier (Ed.), Problems of representation in the teaching and learning of mathematics. Hillsdale, NJ: Lawrence Erlbaum.

Kaminski, J., Sloutsky, V., \& Heckler, A. (2008). The advantage of abstract examples in learning math. Science, 320, 454-455. http://dx.doi.org/10.1126/science.1154659

Kaput, J. J. (1991). Notations and representations as mediators of constructive process. In E. von Glasersfeld (Ed.), Radical constructivism in mathematics education (pp. 53-74). Dordrecht: Kluwer.

Kindt, M., Mabels, M. R. M., \& Pligge, M. (1998). Comparing quantities. In National Center for Research in Mathematical Sciences Education \& Freudenthal Institute (Eds.), Mathematics in Context: A connected curriculum for grades (pp. 5-8). Chicago: Encyclopedia Brittanica Educational Corporation.

Knuth, E. (2002). Secondary school mathematics teachers' conceptions of proof. Journal for Research in Mathematics Education, 33(5), 379-405. http://dx.doi.org/10.2307/4149959

Leinhardt, G., Zaslavsky, O., \& Stein, M. K. (1990). Functions, graphs and graphing: Tasks, learning and teaching. Review of Educational Research, 60(1), 1-64.

Lehrer, R., \& Schauble, L. (2002). Symbolic communication in mathematics and science: Co-constructing inscription and thought. In E. Amsel (Ed.), The development of symbolic communication (pp. 167-192). Mahwah, NJ: Erlbaum.

National Council of Teachers of Mathematics. (2000). Principles and standards for school mathematics. Reston, VA: NCTM.

Meira, L. (2002). Mathematical representations as systems of notations-in-use. In K. Gravenmeijer, R. Lehrer, B. van Oers, \& L. Verschaffel (Eds), Symbolizing, modeling and tool use in mathematics education (pp. 87-104). Dordrecht: Kluwer. http://dx.doi.org/10.1007/978-94-017-3194-2_6

Monk, S. (2003). Representation in school mathematics: Learning to graph and graphing to learn. In J. Kilpatrick (Ed.), A research companion to PSSM (pp. 250-262). Reston, VA: NCTM.

Ochs, E., Jacoby, S., \& Gonzales, P. (1994). Interpretive journeys: How physicists talk and travel through graphic space. Configurations, 2(1), 151-171. http://dx.doi.org/10.1353/con.1994.0003

Olson, D. (1994). The world on paper. Cambridge: Cambridge University Press.

Otte, M. (1994). Mathematical knowledge and the problem of proof. Educational Studies in Mathematics, 26, 299-321. http://dx.doi.org/10.1007/BF01279518

Pimm, D. (1987). Speaking mathematically: Communications in mathematics classrooms. London: Routledge.

RAND Mathematics Study Panel. (2003). Mathematical Proficiency for All Students: Toward a Strategic Research and Development Program in Mathematics Education. Retrieved from http://www.rand.org/multi/achievementforall/math/

Roth, W. M., \& McGinn, M. K. (1997). Graphing: Cognitive ability or practice? Science Education, 81, 91-106. http://dx.doi.org/10.1002/(SICI)1098-237X(199701)81:1<91::AID-SCE5>3.0.CO;2-X

Schoenfeld, A. (1994). What do we know about mathematics curricula? Journal of Mathematical Behavior, 13(1), 55-80. http://dx.doi.org/10.1016/0732-3123(94)90035-3

Schoenfeld, A. H. (2009). The soul of mathematics. In D. Stylianou, M. Blanton, \& E. Knuth (Eds.), Teaching and learning proof across the grades: A K-16 perspective (pp. xii-xvi). Mahwah, NJ: Taylor \& Francis Group. 
Sfard, A. (2000). Steering (dis)course between metaphors and rigor. Journal for Research in Mathematics Education, 31(3), 296-327. http://dx.doi.org/10.2307/749809

Silver, E., Ghousseini, H., Gosen, D., Charalambous, C., \& Font Strawhun, B. (2005). Moving from rhetoric to praxis: Issues faced by teachers in having students consider multiple solutions for problems in the mathematics classroom. Journal of Mathematical Behavior, 24, 287-301. http://dx.doi.org/10.1016/j.jmathb.2005.09.009

Simon, D., \& Simon, H. (1978). Individual differences in solving physics problems. In Siegler (Ed.), Children's thinking: What develops? (pp. 325-348). Hillsdale, NJ: Lawrence Erlbaum Associate, Inc.

Steffe, L., \& Kieren, T. (1994). Radical constructivism and mathematics education. Journal for Research in Mathematics Education, 25, 711-733. http://dx.doi.org/10.2307/749582

Stein, M. K., Engle, R., Smith, M., \& Hughes, E. (2008). Orchestrating productive mathematical discussions: Five practices for helping teachers move beyond show and tell. Mathematical Thinking and Learning, 10, 313-340. http://dx.doi.org/10.1080/10986060802229675

Stein, M. K., Smith, M. S., Henningsen, M. A., \& Silver, E. A. (2010). Implementing standards-based mathematics instruction: A casebook for professional development. New York: Teachers College Press.

Stylianou, D. (2002). Interaction of visualization and analysis the negotiation of a visual representation in problem solving. Journal of Mathematical Behavior, 21, 303-307. http://dx.doi.org/10.1016/S0732-3123(02)00131-1

Stylianou, D. (2010). Teachers' conceptions of representation in the context of middle school mathematics. Journal of Mathematics Teacher Education, 13(4), 325-343. http://dx.doi.org/10.1007/s10857-010-9143-y

Stylianou, D. A. (2011). An examination of middle school students' representation practices in mathematical problem solving through the lens of expert work: Towards an organizing scheme. Educational Studies in Mathematics, 76, 265-280. http://dx.doi.org/10.1007/s10649-010-9273-2

Stylianou, D. A., \& Silver, E. A. (2004). The role of visual representations in advanced mathematical problem solving: An examination of expert-novice similarities and differences. Journal of Mathematical Thinking and Learning, 6(4), 353-387. http://dx.doi.org/10.1207/s15327833mt10604_1

Thompson, P. (1988). Quantitative concepts as a foundation for algebra. In Proceedings of the $10^{\text {th }}$ Annual Meeting of PME-NA (Vol. 1, pp. 163-170). Columbus, OH: ERIC

Weber, K. (2001). Student difficulty in constructing proofs: The need for strategic knowledge. Educational Studies in Mathematics, 48, 101-119. http://dx.doi.org/10.1023/A:1015535614355

Weber, K., \& Alcock, L. (2009). Proof in advanced mathematics classes: Semantic and syntactic reasoning in the representation system of proof. In D. Stylianou, M. Blanton, \& E. Knuth (Eds.), Teaching and learning proof across the grades: A K-16 perspective (pp. 323-338). Mahwah, NJ: Taylor \& Francis Group. 